\title{
Meteorological Drought Index Mapping in Bangladesh Using Standardized Precipitation Index during 1981-2010
}

\author{
Md. Anarul Haque Mondol, ${ }^{1}$ Iffat Ara, ${ }^{1,2}$ and Subash Chandra Das ${ }^{1}$ \\ ${ }^{1}$ Department of Geography and Environment, Jahangirnagar University, Savar, Dhaka 1342, Bangladesh \\ ${ }^{2}$ School of Biological Sciences, University of Adelaide, Adelaide, SA 5005, Australia \\ Correspondence should be addressed to Md. Anarul Haque Mondol; anarulju@gmail.com
}

Received 25 August 2016; Revised 31 December 2016; Accepted 18 January 2017; Published 20 March 2017

Academic Editor: Roberto Fraile

Copyright (c) $2017 \mathrm{Md}$. Anarul Haque Mondol et al. This is an open access article distributed under the Creative Commons Attribution License, which permits unrestricted use, distribution, and reproduction in any medium, provided the original work is properly cited.

\begin{abstract}
Natural disasters are a major concern in Bangladesh, particularly drought which is one of the most common disaster in Bangladesh. Drought needs to be explained spatially to understand its spatiotemporal variations in different areas. In this paper, the meteorological drought has been shown by using the Standardized Precipitation Index (SPI) method and illustrated through the Inverse Distance Weighted (IDW) method across Bangladesh. We used rainfall data of 30 meteorological stations in Bangladesh during the study period of 1981-2010. The results indicate that drought has been fluctuating and it has become a recurrent phenomenon during the study period. The SPI depicted the drought conditions that plunged dramatically in 1981, 1982, 1985, 1987, 1989, 1992, 1994, and 1996 and then gradually improved in 2004, 2006, and 2009 in the country. The present study demonstrated that drought occurred in Bangladesh on an average of 2.5 years. Drought was more prominent in the northern, south-western, and eastern regions in Bangladesh compared to the rest of the areas of the country. The outcomes of the present study will help in during disaster management strategies, particularly drought, by initiating effective plans and adaptation remedies in different areas of Bangladesh.
\end{abstract}

\section{Introduction}

Globally many countries have become vulnerable to drought due to climate change and other natural conditions [1]. Drought is one of the key natural disaster in Bangladesh [2]. It has become a major concern in the country, particularly in terms of Bangladesh agricultural production and environmental damage. It adversely impacts agricultural production and natural environment [3], mostly areas in the northwestern part $[4,5]$. Mapping drought is necessary to understand the regional severity of drought to manage it effectively and to reduce the agricultural production losses and protect the environment.

Drought is mainly agricultural, meteorological, hydrological, and social. Meteorological drought is defined on the basis of the degree of dryness and the severity of drought in a region [6]. Meteorological drought was assessed through annual rainfall [7]. For instance, annual rainfall between 25\% and $50 \%$ deficiency was considered as moderate drought whereas annual rainfall less than the value of $50 \%$ deficiency was considered as severe drought in a region. Moreover, a year was considered as a drought year when the total area of the country was affected individually with more than $20 \%$ deficiency of annual rainfall [8].

Bangladesh has experienced drought frequently over the past years $[9,10]$. Despite the recurrent and devastating nature of drought in different areas of Bangladesh, it has received far less attention compared to flood [11]. However, drought should be assessed importantly [12] to understand its magnitude [13] in different areas [14] from the past meteorological records $[1,15]$. Meteorological information, particularly regional rainfall evidence [16], is the common way of drought diagnosis by using GIS technique [17, 18]. Spatially explicit drought conditions may offer valuable concerns through this technique $[19,20]$, which needs to be applied in case of Bangladesh drought assessment. Several studies have been carried out on droughts and related issues in Bangladesh [21, 22 . Most of the researches in Bangladesh are mainly on agricultural drought and region-based [23]. For instance, a study conducted by Alam et al. [23, 24] showed the spatial extent of 
agricultural drought in Barind regions of Bangladesh by using statistical measure. Spatiotemporal extent of drought was also analyzed by Akter and Rahman [25] which indicated the adverse impact of shortage of seasonal rainfall and its consequences on drought by using Rainfall Anomaly Index (RDI). An analysis of drought in eastern part of Bangladesh shows that drought occurred mainly in November-March in these regions and sometimes in April, September, and October [8]. Drought assessment in the western part of Bangladesh was conducted by Shahid and Behrawan [26]. An Standardized Precipitation Index (SPI) based on drought analysis of three, five, and twelve months indicated that drought followed almost a similar spatial pattern in the Barind tract area of Bangladesh [23]. Another SPI based drought analysis was conducted in Bangladesh to analyze the meteorological drought using the rainfall information of 27 meteorological stations of Bangladesh [27]. Recently, some research on meteorological drought has been performed by Alamgir et al. [18] for different cropping and climatic seasons of Bangladesh. Although meteorological drought was used in some studies in Bangladesh to assess drought conditions, few studies assessed drought conditions including this spatial extent. However, the less explored area of drought analysis at broader scale included different areas of Bangladesh to understand spatial variability of drought across the country by using the past rainfall records.

There are few studies which illustrated drought spatially. Likewise, the first agricultural drought risk map of Bangladesh was prepared by Karim et al. [28], which considered the cumulative effect of dry days, seasonal higher temperatures, and soil moisture availability. WARPO-EGIC illustrated drought-prone areas in Bangladesh [29]. Similarly, seasonal drought risk maps were prepared in the country [30]. In general, drought mapping in Bangladesh principally covered the seasonal extent to reduce the agricultural risks alone. Drought was assessed through different methods globally $[3,31]$. However, spatiotemporal pattern of meteorological drought [32] that is principally based on meteorological information is still unexplored for the purpose of understanding the further conditions of drought in different areas of Bangladesh. Though few studies focused on meteorological drought, model based studies in a broader scale are rare. Several studies conducted drought research in different regions of Bangladesh individually by using weather information from few stations. However, the spatiotemporal extents of the previous studies are too small to understand regional drought conditions in detail. In this research, maximum number of rainfall stations and long period of time (1948-2010) has been used which certainly provides more details of regional drought conditions across Bangladesh than any other past researches. One of the major contributions of the present research is that the research illustrates the places where drought occurred every year during the period of 1981-2010. Therefore, this will help to understand regional drought conditions to the respective years. In this research, identification of droughts of different time periods of the year is considered including short-term (January-March); medium short-term (January-June); and yearly or long-term

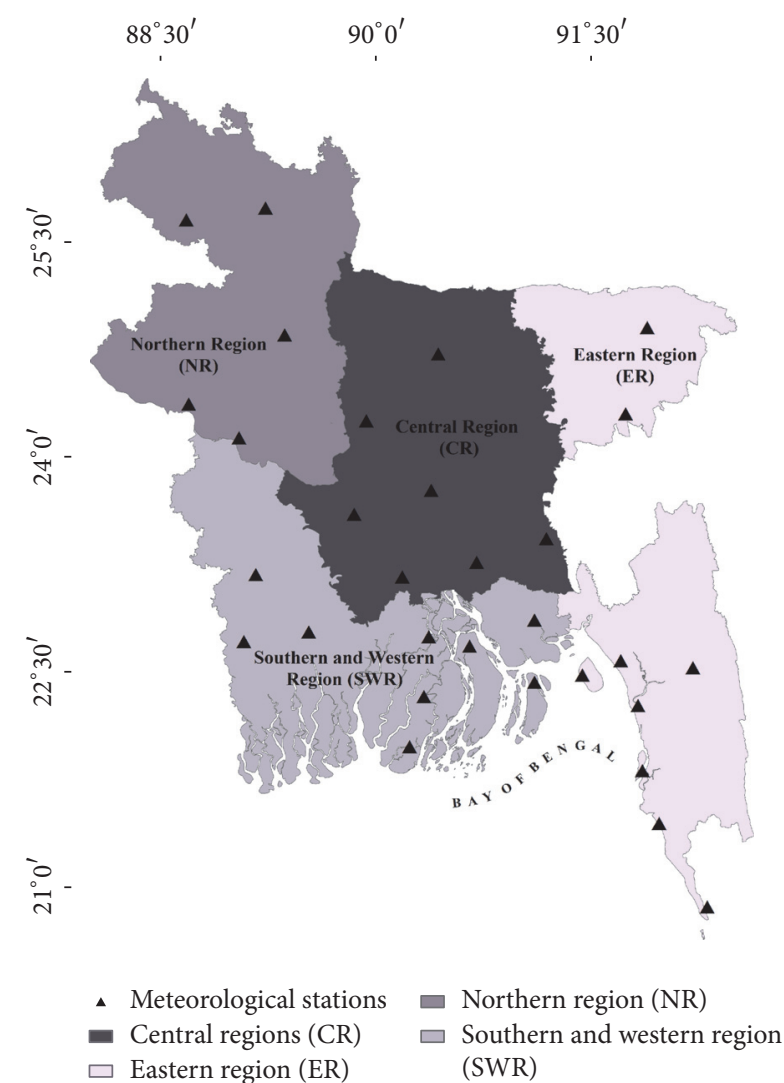

FIGURE 1: Location of meteorological stations (triangles) and regional divisions of the study area. Source: [32].

(January-December) based on previous research [33]. However, the present study extends regional variation of drought conditions across Bangladesh during the period of 1981-2010. According to regional drought assessment gaps, the aim of the present study is to characterize the spatial and temporal pattern of meteorological drought across Bangladesh by using Standardized Precipitation Index (SPI) [34].

\section{Methods}

2.1. Study Area. The study area covers Bangladesh that is located in the tropics between $20^{\circ} 34^{\prime}$ and $26^{\circ} 38^{\prime}$ north latitudes and $88^{\circ} 01^{\prime}$ and $92^{\circ} 41^{\prime}$ east longitudes. In the present study, the 30 meteorological stations of Bangladesh Meteorological Department (BMD) were selected on the basis of the data for the study period of 1981 to 2010 (Figure 1).

2.2. Rainfall Data. The data of rainfall of Bangladesh were obtained from the Bangladesh Meteorological Department (BMD). Monthly data of average rainfall over Bangladesh have been collected for a maximum period of 64 years, 1948-2011. Time series of 30 meteorological stations were then used for the period of 1981 to 2010 in the present study.

2.3. SPI Calculation and Drought Categories. There are many more drought indices to detect, analyze, and predict the drought related issues. The most commonly used drought 
indices are Standardized Precipitation Index (SPI) and Palmer Drought Severity Index (PDSI) [16]. Standardized Precipitation Index (SPI) is more flexible and simpler than other indices. This model of drought indices allows temporal analysis of drought in all time periods. As only single variable, rainfall is used for input and can help to take decision and predict drought easily. SPI analysis is suited for different time periods [34].

The SPI classification is based on three-month, six-month, and twelve-month calculation in the present study [8]. Here three-month SPI covers January, February, and March. The six-month SPI covers the period of January-June and the twelve-month SPI covers the period of January-December. Three-month SPI indicates the conditions of short-term drought of the area while six-month SPI indicates medium short-term drought and twelve-month SPI indicates longterm drought of an area. The analysis of the SPI was performed by the Drought Index Calculator (DrinC), which was developed by the Laboratory of Reclamation Works \& Water Resources Management, National Technical University of Athens [35]. The software was downloaded from http:// www.ewra.net/drinc in 1st of June, 2013. The index is mainly based on an equiprobability transformation [36] and numerically depends on the combined likelihood of a given precipitation occasion happening at a station. The noteworthy precipitation information of the station is fitted to a gamma appropriation, as the gamma transformation (1) has been found to fit the precipitation conveyance entirely well. Before this the mean, standard deviation and the rainfall data were transformed by the $\log$ (In) and then the mean was calculated and also constant U, shape, and scale. The gamma transformation was done using $t$-transformation (2) and SPI (3) was then calculated from some magnitude of the gamma transformed values of $c_{0}=2.5155517, c_{1}=0.802853, c_{2}=$ $0.010328, d_{1}=1.432788, d_{2}=0.189269$, and $d_{3}=.001308$ [37].

Cumulative Gamma transform $=G(x)$

$$
\begin{aligned}
& =\frac{1}{\alpha^{\beta} \Gamma \beta} \int_{0}^{x} x^{\beta-1} e^{-x / \alpha} d x \\
& t \text { transform }=t=\sqrt{\ln \left\lceil\frac{1}{X_{g}}\right\rceil}, \quad \text { where } X_{g} \leq 0.5 \\
& \text { or, } t \text { transform }=t=\sqrt{\ln \left[\frac{1}{1-X_{g}}\right\rceil} \\
& \text { where } X_{g} \leq 1.0 \\
& \mathrm{SPI}=-\left\lceil t-\frac{c_{0}+c_{1} t+c_{2} t^{2}}{1+d_{1} t+d_{2} t^{2}+d_{3} t^{3}}\right\rceil, \\
& \text { where } X_{g} \leq 0.5 \\
& \text { or, } \mathrm{SPI}=+\left\lceil t-\frac{c_{0}+c_{1} t+c_{2} t^{2}}{1+d_{1} t+d_{2} t^{2}+d_{3} t^{3}}\right\rceil \text {, } \\
& \text { where } X_{g} \leq 1.0 \text {. }
\end{aligned}
$$

\section{TABLE 1: Drought categories.}

\begin{tabular}{lc}
\hline SPI values & Drought category \\
\hline$>0$ & No drought \\
$<0$ to -0.99 & Normal/mild drought \\
-1.00 to -1.49 & Moderate drought \\
-1.50 to -1.99 & Severe drought \\
-2.00 and less & Extreme drought \\
\hline
\end{tabular}

The statistical significance of the differences among the three periods at each station was assessed using a Kruskal-Wallis test.

The following drought categories were used during the study (Table 1).

2.4. Drought Index Mapping and Justification of Use of IDW. The Geographic Information System (GIS) has been used for the mapping drought index. The Inverse Distance Weighted (IDW) method was considered in the study to interpolate the SPI station based results across Bangladesh where the power was considered as 2 , the searching neighborhood was standard, including at least 10 neighborhoods, neighbors to include 15, major semiaxis was 1.52, minor semiaxis was 1.52, and the angle was 0 . The Inverse Distance Weighting (IDW) is an established deterministic methods for SPI mapping $[16,38-40]$ and one of the most frequently used deterministic models in spatial interpolation [41]. The IDW is the simple and intuitive deterministic interpolation method based on principle that sample values closer to the prediction location have more influence on the prediction value than sample values farther apart [42].

\section{Results and Discussions}

The results indicated that there were significant changes in spatial and temporal conditions of drought in Bangladesh over the period of 1981-2010. The results of the present study demonstrated that drought is recurrent; and the vulnerability of drought varies spatially and temporarily. On average, drought occurred every 2.5 years in the country. Significant changes were found in the SPI index among 1981-2010 in three-month, six-month, and twelve-month SPI interfaces.

3.1. Meteorological Drought Statistics (Number, Percentages, and Normal QQ Plot) of Bangladesh. The data of the number of drought years and percentage of 30 years (1981-2010) on the basis of three-month (January-March) SPI has been shown in Table 2. $N$ represents the number of years of extreme, severe, moderate, and normal droughts in the respective stations. By adding the values of $N$ it can be found that high number of drought years existed in places like Rangamati, Ishurdi, and Satkhira. Rangamati had 17, Ishurdi and Satkhira had 16, Teknaf had 15, and Comilla and M. Court had 14 years of total drought. The percentage of extreme drought was highest (10\%) in Comilla, Madaripur, and Patuakhali. On the other hand, Dinajpur had the highest percentage $(47 \%)$ in case of normal drought. The lowest percentage of normal drought (10\%) was found in Hatiya and Jessore. The 
TABLE 2: Number of drought years and percentage based on three-month SPI.

\begin{tabular}{|c|c|c|c|c|c|c|c|c|}
\hline \multirow{3}{*}{ Station name } & \multicolumn{8}{|c|}{ Drought types } \\
\hline & \multicolumn{2}{|c|}{ Extreme } & \multicolumn{2}{|c|}{ Severe } & \multicolumn{2}{|c|}{ Moderate } & \multicolumn{2}{|c|}{ Normal } \\
\hline & $N$ & $\%$ & $N$ & $\%$ & $N$ & $\%$ & $N$ & $\%$ \\
\hline Barisal & 0 & 0 & 1 & 3 & 0 & 0 & 9 & 30 \\
\hline Bhola & 1 & 3 & 4 & 13 & 2 & 7 & 6 & 20 \\
\hline Bogra & 0 & 0 & 1 & 3 & 4 & 13 & 8 & 27 \\
\hline Chandpur & 2 & 7 & 2 & 7 & 2 & 7 & 7 & 23 \\
\hline Chittagong & 2 & 7 & 0 & 0 & 5 & 17 & 5 & 17 \\
\hline Comilla & 3 & 10 & 1 & 3 & 1 & 3 & 9 & 30 \\
\hline Cox's Bazar & 0 & 0 & 2 & 7 & 3 & 10 & 9 & 30 \\
\hline Dhaka & 0 & 0 & 2 & 7 & 5 & 17 & 4 & 13 \\
\hline Dinajpur & 0 & 0 & 0 & 0 & 2 & 7 & 14 & 47 \\
\hline Faridpur & 0 & 0 & 0 & 0 & 4 & 13 & 11 & 37 \\
\hline Hatiya & 1 & 3 & 3 & 10 & 4 & 13 & 3 & 10 \\
\hline Ishurdi & 0 & 0 & 1 & 3 & 3 & 10 & 12 & 40 \\
\hline Jessore & 0 & 0 & 2 & 7 & 3 & 10 & 3 & 10 \\
\hline Khepupara & 2 & 7 & 3 & 10 & 0 & 0 & 6 & 20 \\
\hline Khulna & 0 & 0 & 1 & 3 & 3 & 10 & 8 & 27 \\
\hline Kutubdia & 0 & 0 & 1 & 3 & 3 & 10 & 12 & 40 \\
\hline M. Court & 2 & 7 & 2 & 7 & 4 & 13 & 6 & 20 \\
\hline Madaripur & 3 & 10 & 1 & 3 & 1 & 3 & 8 & 27 \\
\hline Mymensinghh & 0 & 0 & 4 & 13 & 0 & 0 & 7 & 23 \\
\hline Patuakhali & 3 & 10 & 0 & 0 & 2 & 7 & 7 & 23 \\
\hline Rajshahi & 0 & 0 & 1 & 3 & 4 & 13 & 11 & 37 \\
\hline Rangamati & 1 & 3 & 2 & 7 & 3 & 10 & 11 & 37 \\
\hline Rangpur & 0 & 0 & 1 & 3 & 0 & 0 & 9 & 30 \\
\hline Sandwip & 0 & 0 & 2 & 7 & 3 & 10 & 7 & 23 \\
\hline Satkhira & 0 & 0 & 2 & 7 & 4 & 13 & 10 & 33 \\
\hline Sitakunda & 1 & 3 & 1 & 3 & 2 & 7 & 10 & 33 \\
\hline Srimangal & 0 & 0 & 3 & 10 & 3 & 10 & 10 & 33 \\
\hline Sylhet & 1 & 3 & 2 & 7 & 1 & 3 & 10 & 33 \\
\hline Tangail & 1 & 3 & 2 & 7 & 1 & 3 & 10 & 33 \\
\hline Teknaf & 0 & 0 & 4 & 13 & 1 & 3 & 10 & 33 \\
\hline
\end{tabular}

capital Dhaka had the second lowest percentage of normal drought (13\%) (Table 2).

Again, the data of the number of drought years and percentage of 30 years (1981-2010) based on six-month (January-June) SPI has been shown in Table 3. $N$ represents the number of years of extreme, severe, moderate, and normal droughts in the respective stations. By adding the values of $N$ it can be found that Rajshahi and Rangamati had the highest number of total drought years which is 16. Many stations including Bhola, Comilla, Cox's Bazar, Ishurdi, Jessore, M. Court, Sitakunda, and Srimangal had a total 15 years of different types of droughts. The highest percentage of normal drought (50\%) was found in Dinajpur while the lowest (17\%) occurred in Chittagong and Dhaka. Khepupara had the highest percentage (10\%) of extreme drought during this period.

The data of the number of drought years and percentage of 30 years (1981-2010) on the basis of twelve-month (January-December) SPI has been shown in Table 4. N represents the number of years of extreme, severe, moderate, and normal droughts in the respective stations. By adding the values of $N$ it can be found that Rajshahi had the highest number of total drought years which is 20. Chadpur, Faridpur, and Ishurdi had 17 years and Bhola, Chittagong, Comilla, Tangail, and Teknaf had 15 years of total drought. The percentage of normal drought was highest $(57 \%)$ in Rajshahi. Chittagong and Faridpur too had high (43) percentage of normal drought. The lowest percentage (10) of normal drought was found in Srimangal. M. Court had the highest percentage $(7 \%)$ of extreme drought in this period.

The normal QQ plot (Figures 2, 3, and 4) indicates that most of the data are approximately normally distributed except the data of 1993 (Figure 4) based on twelve-month SPI analysis. This indicates that the data are from gamma distribution. The normal plot is approximately a straight line, so we can conclude that the original dataset is close to normally distributed. 
TABLE 3: Number of drought years and percentage based on six-month SPI.

\begin{tabular}{|c|c|c|c|c|c|c|c|c|}
\hline \multirow{3}{*}{ Station name } & \multicolumn{8}{|c|}{ Drought types } \\
\hline & \multicolumn{2}{|c|}{ Extreme } & \multicolumn{2}{|c|}{ Severe } & \multicolumn{2}{|c|}{ Moderate } & \multicolumn{2}{|c|}{ Normal } \\
\hline & $N$ & $\%$ & $N$ & $\%$ & $N$ & $\%$ & $N$ & $\%$ \\
\hline Barisal & 0 & 0 & 1 & 3 & 0 & 0 & 12 & 40 \\
\hline Bhola & 1 & 3 & 1 & 3 & 3 & 10 & 10 & 33 \\
\hline Bogra & 0 & 0 & 1 & 3 & 5 & 17 & 6 & 20 \\
\hline Chandpur & 1 & 3 & 1 & 3 & 3 & 10 & 7 & 23 \\
\hline Chittagong & 0 & 0 & 3 & 10 & 2 & 7 & 5 & 17 \\
\hline Comilla & 1 & 3 & 3 & 10 & 1 & 3 & 10 & 33 \\
\hline Cox’s Bazar & 1 & 3 & 1 & 3 & 3 & 10 & 10 & 33 \\
\hline Dhaka & 2 & 7 & 0 & 0 & 3 & 10 & 5 & 17 \\
\hline Dinajpur & 0 & 0 & 0 & 0 & 2 & 7 & 15 & 50 \\
\hline Faridpur & 1 & 3 & 0 & 0 & 1 & 3 & 12 & 40 \\
\hline Hatiya & 2 & 7 & 1 & 3 & 2 & 7 & 6 & 20 \\
\hline Ishurdi & 1 & 3 & 1 & 3 & 1 & 3 & 12 & 40 \\
\hline Jessore & 1 & 3 & 0 & 0 & 2 & 7 & 12 & 40 \\
\hline Khepupara & 3 & 10 & 0 & 0 & 0 & 0 & 10 & 33 \\
\hline Khulna & 0 & 0 & 2 & 7 & 2 & 7 & 8 & 27 \\
\hline Kutubdia & 0 & 0 & 1 & 3 & 0 & 0 & 12 & 40 \\
\hline M. Court & 1 & 3 & 1 & 3 & 4 & 13 & 9 & 30 \\
\hline Madaripur & 2 & 7 & 0 & 0 & 3 & 10 & 9 & 30 \\
\hline Mymensinghh & 2 & 7 & 0 & 0 & 2 & 7 & 6 & 20 \\
\hline Patuakhali & 1 & 3 & 1 & 3 & 1 & 3 & 10 & 33 \\
\hline Rajshahi & 0 & 0 & 1 & 3 & 4 & 13 & 11 & 37 \\
\hline Rangamati & 0 & 0 & 2 & 7 & 1 & 3 & 13 & 43 \\
\hline Rangpur & 0 & 0 & 1 & 3 & 0 & 0 & 12 & 40 \\
\hline Sandwip & 1 & 3 & 0 & 0 & 1 & 3 & 11 & 37 \\
\hline Satkhira & 0 & 0 & 1 & 3 & 5 & 17 & 9 & 30 \\
\hline Sitakunda & 1 & 3 & 0 & 0 & 1 & 3 & 13 & 43 \\
\hline Srimangal & 1 & 3 & 1 & 3 & 4 & 13 & 9 & 30 \\
\hline Sylhet & 0 & 0 & 2 & 7 & 2 & 7 & 7 & 23 \\
\hline Tangail & 1 & 3 & 2 & 7 & 2 & 7 & 8 & 27 \\
\hline Teknaf & 1 & 3 & 1 & 3 & 3 & 10 & 8 & 27 \\
\hline
\end{tabular}

3.2. Spatiotemporal Extents of Meteorological Drought in Bangladesh. The results indicated that temporarily the rainfall intensity, duration, and spatial consequences had a strong anomaly. Therefore, the country experienced shortterm drought conditions (three-month SPI), medium shortterm drought conditions (six-month drought), and often long-term drought (12-month drought) conditions. Further, some of the years had normal drought conditions across the country, though the magnitudes were low in SPI scales. These were experienced as mild or normal type drought over the study period (Tables 2, 3, and 4). Therefore, mild or normal type drought frequently occurred in the country (Tables 2, 3, and 4 ).

Drought varied spatially in Bangladesh over the study period. Some areas had no drought in the short term (threemonth SPI) (Figures 5, 6, and 7) and medium short-term interval (six-month SPI) whereas these areas had drought in the long term (twelve-month SPI). Again some areas had drought in short term or in medium short-term period whereas there was no drought in long term. These also happened in some cases independently in the SPI interval. The result indicated that the drought conditions were dynamic across Bangladesh (Figures 5, 6, and 7). Some areas, like the north and southern-eastern parts of the country, had drought almost in every drought year.

3.3. Assessment of Drought in the Decade of 1981-1990 in Bangladesh. Figure 5 marks the drought conditions of different parts of Bangladesh during 1981-1990. The first three maps (Figures 5(a), 5(b), and 5(c)) show the conditions of 1981 having the time intervals of 3,6 , and 12 months, respectively. The map of the 3-month SPI (Figure 5(a)) shows extreme drought in few parts of Chittagong district. Most of the areas 
TABLE 4: Number of drought years and percentage based on twelve-month SPI.

\begin{tabular}{|c|c|c|c|c|c|c|c|c|}
\hline \multirow{3}{*}{ Station name } & \multicolumn{8}{|c|}{ Drought types } \\
\hline & \multicolumn{2}{|c|}{ Extreme } & \multicolumn{2}{|c|}{ Severe } & \multicolumn{2}{|c|}{ Moderate } & \multicolumn{2}{|c|}{ Normal } \\
\hline & $N$ & $\%$ & $N$ & $\%$ & $N$ & $\%$ & $N$ & $\%$ \\
\hline Barisal & 0 & 0 & 0 & 0 & 1 & 3 & 8 & 27 \\
\hline Bhola & 0 & 0 & 0 & 0 & 4 & 13 & 11 & 37 \\
\hline Bogra & 0 & 0 & 0 & 0 & 4 & 13 & 7 & 23 \\
\hline Chandpur & 1 & 3 & 3 & 10 & 2 & 7 & 11 & 37 \\
\hline Chittagong & 1 & 3 & 0 & 0 & 1 & 3 & 13 & 43 \\
\hline Comilla & 0 & 0 & 2 & 7 & 2 & 7 & 11 & 37 \\
\hline Cox’s Bazar & 0 & 0 & 0 & 0 & 2 & 7 & 9 & 30 \\
\hline Dhaka & 2 & 7 & 0 & 0 & 2 & 7 & 9 & 30 \\
\hline Dinajpur & 0 & 0 & 1 & 3 & 2 & 7 & 9 & 30 \\
\hline Faridpur & 1 & 3 & 0 & 0 & 3 & 10 & 13 & 43 \\
\hline Hatiya & 1 & 3 & 2 & 7 & 3 & 10 & 7 & 23 \\
\hline Ishurdi & 0 & 0 & 2 & 7 & 3 & 10 & 12 & 40 \\
\hline Jessore & 0 & 0 & 0 & 0 & 1 & 3 & 10 & 33 \\
\hline Khepupara & 0 & 0 & 0 & 0 & 1 & 3 & 11 & 37 \\
\hline Khulna & 0 & 0 & 0 & 0 & 5 & 17 & 7 & 23 \\
\hline Kutubdia & 0 & 0 & 0 & 0 & 2 & 7 & 10 & 33 \\
\hline M. Court & 2 & 7 & 0 & 0 & 3 & 10 & 8 & 27 \\
\hline Madaripur & 0 & 0 & 4 & 13 & 2 & 7 & 7 & 23 \\
\hline Mymensinghh & 0 & 0 & 1 & 3 & 3 & 10 & 8 & 27 \\
\hline Patuakhali & 0 & 0 & 0 & 0 & 3 & 10 & 12 & 40 \\
\hline Rajshahi & 0 & 0 & 2 & 7 & 1 & 3 & 17 & 57 \\
\hline Rangamati & 0 & 0 & 1 & 3 & 2 & 7 & 9 & 30 \\
\hline Rangpur & 0 & 0 & 0 & 0 & 1 & 3 & 8 & 27 \\
\hline Sandwip & 0 & 0 & 1 & 3 & 2 & 7 & 9 & 30 \\
\hline Satkhira & 0 & 0 & 1 & 3 & 1 & 3 & 9 & 30 \\
\hline Sitakunda & 0 & 0 & 0 & 0 & 0 & 0 & 8 & 27 \\
\hline Srimangal & 0 & 0 & 3 & 10 & 7 & 23 & 3 & 10 \\
\hline Sylhet & 0 & 0 & 0 & 0 & 2 & 7 & 8 & 27 \\
\hline Tangail & 1 & 3 & 2 & 7 & 1 & 3 & 11 & 37 \\
\hline Teknaf & 0 & 0 & 3 & 10 & 2 & 7 & 10 & 33 \\
\hline
\end{tabular}

in the south-east part of the country experienced greater drought. The rest of the parts of the country except Ishurdi faced normal or mild drought.

The map of 6 months SPI (Figure 5(b)) shows that most of the parts of the country faced normal or mild drought. Rajshahi and Khulna had no drought while Comilla faced severe drought. The map of 12-month SPI (Figure 5(c)) shows that most of the areas of the country had no drought. Most of the parts of Chittagong faced normal or mild drought. Few parts of Rangpur and Dhaka had normal or mild drought too. The maps (Figures 5(d), 5(e), and 5(f)) show the conditions of 1982. The map of 3-month SPI shows extreme drought in few regions of Sylhet and Chittagong. The north-eastern and south-western parts of the country happened to face more drought during this period. Severe drought was found in Khulna. The rest of the parts of the country including Rangpur, Rajshahi and Dhaka had normal or mild drought (Figure 5(d)).
Again extreme drought was found in the north-eastern part of the country. Severe drought existed in Sylhet, Chittagong, Khulna, and Barisal (Figure 5(e)). The map of 12 months had scattered distributions. Few regions of Rangpur, Sylhet, Comilla, and Cox's Bazar had no drought. Most of the regions of the country had normal or mild drought while few areas in the north-eastern part of the country had severe drought. Few parts of Dhaka and Chittagong faced severe drought (Figure 5(f)) too. The maps (Figures 5(g), 5(h), and 5(i)) show the conditions of 1983 based on an interval of 3 , 6 , and 12 months, respectively. Most of the parts of the country faced no drought and normal drought was found in some areas of Sylhet and Chittagong based on three-month SPI map (Figure 5(g)). No drought was seen in most of the parts of the country (Figure 5(i)). Maijdi and Comilla faced normal drought (Figure 5(h)). No drought was seen in most of the regions of Rangpur, Rajshahi, Mymensingh, and Sylhet in 1984 based on three-month SPI (Figure 5(j)). 

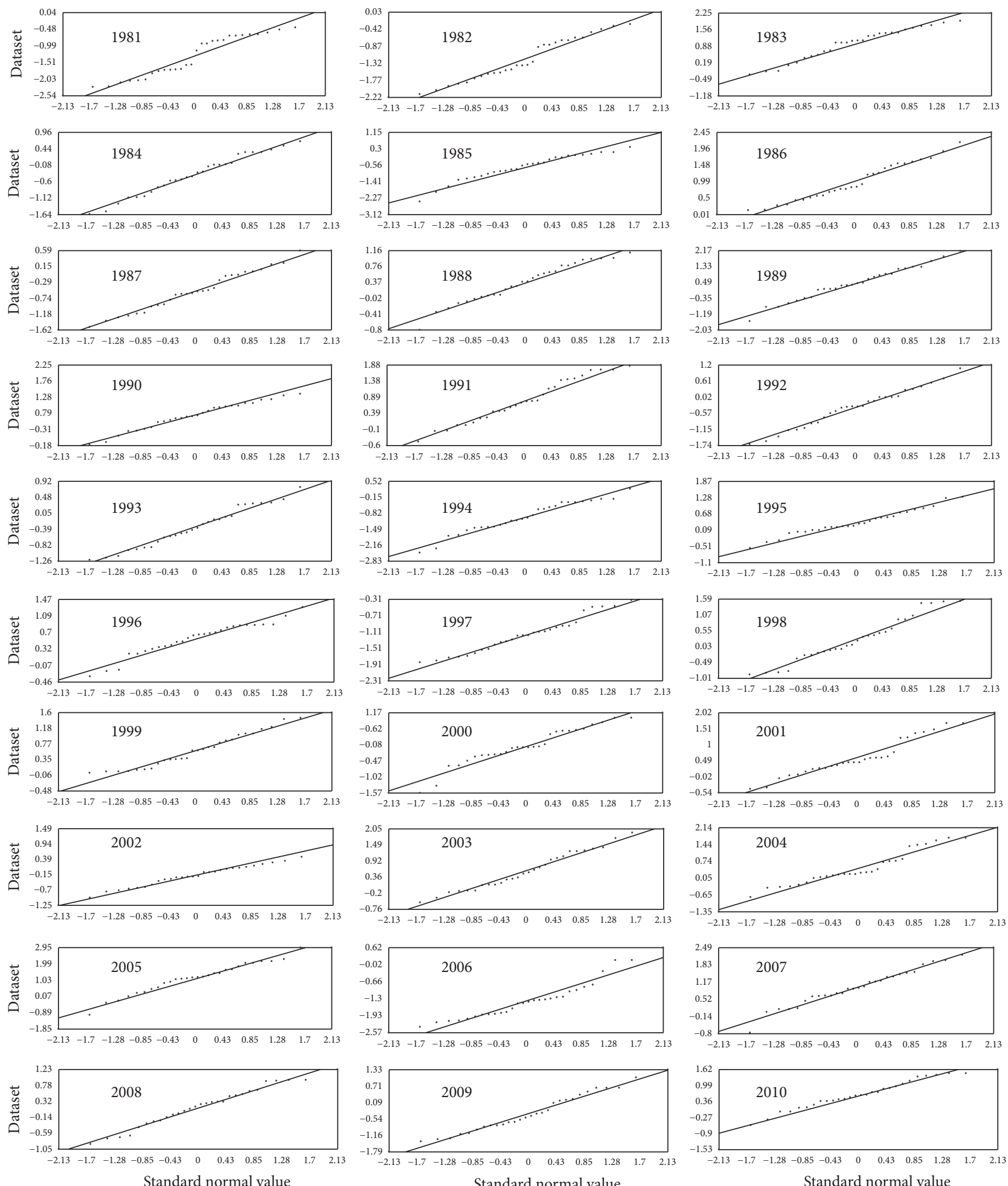

FIGURE 2: Normal QQ plot based on three-month SPI over the period of 1981-2010 for 30 meteorological stations of Bangladesh (horizontal axis represents the standard normal value and vertical axis represents the datasets of SPI). 

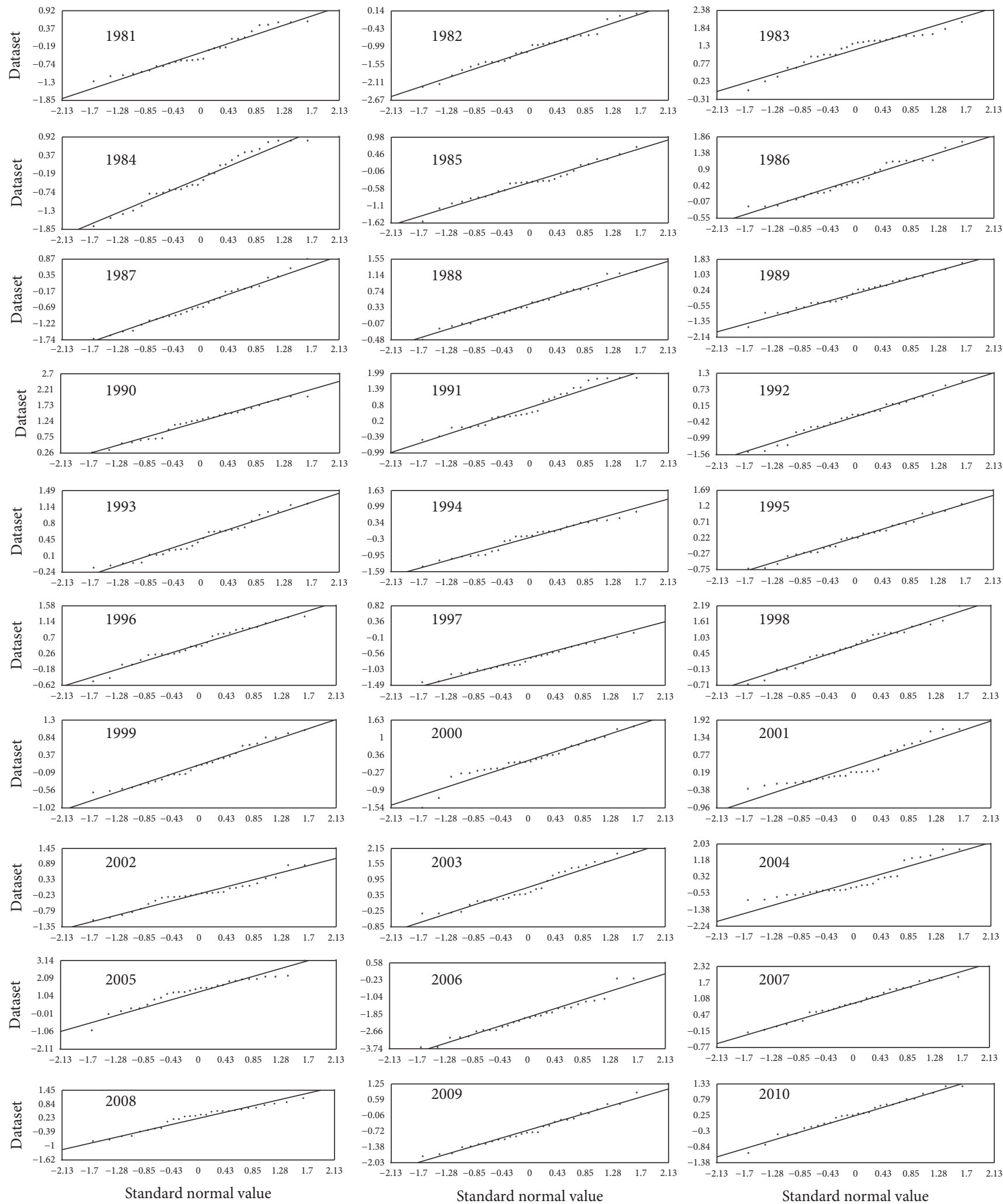

FIGURE 3: Normal QQ plot based on six-month SPI over the period of 1981-2010 for 30 meteorological stations of Bangladesh (horizontal axis represents the standard normal value and vertical axis represents the datasets of SPI). 

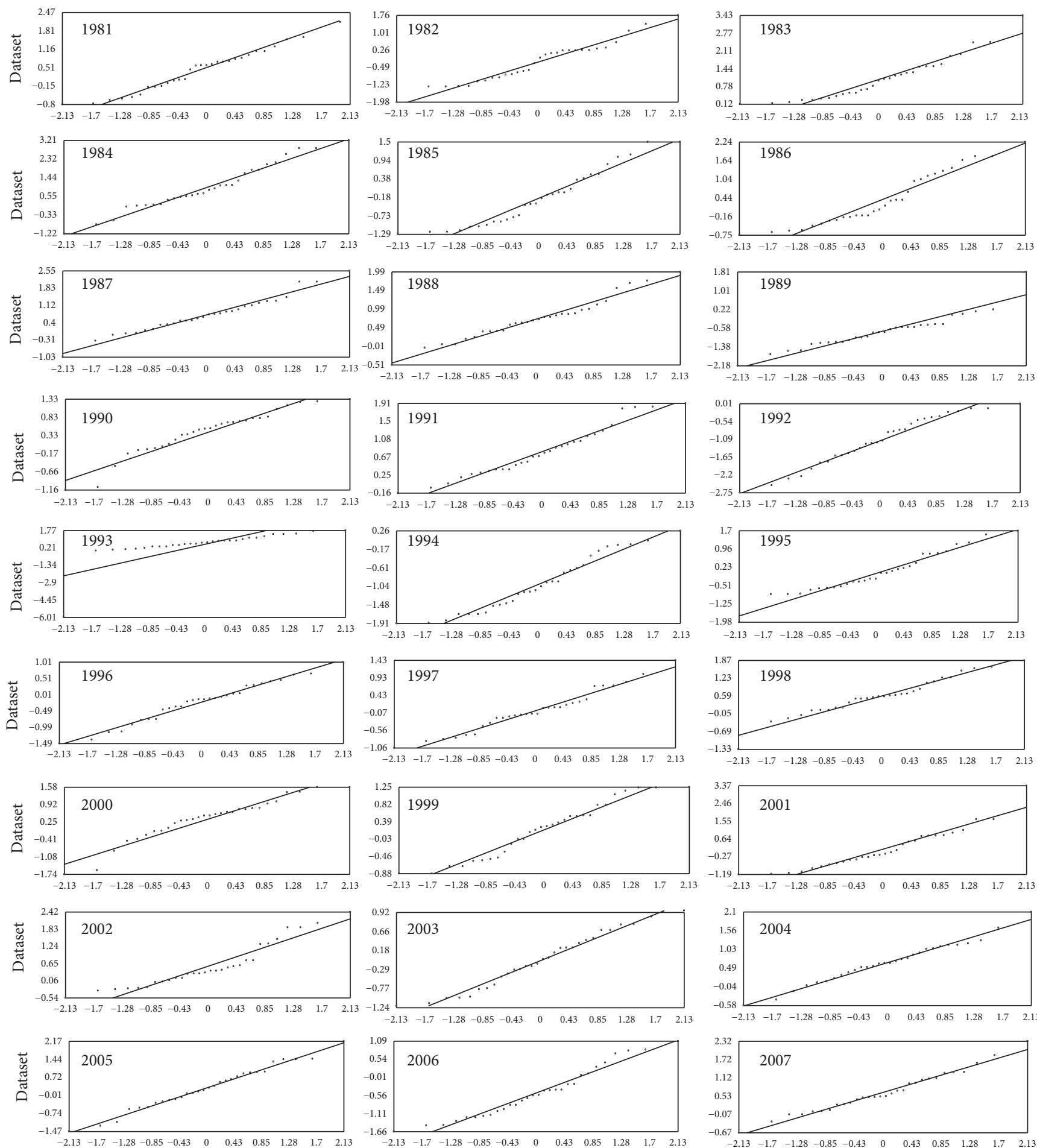

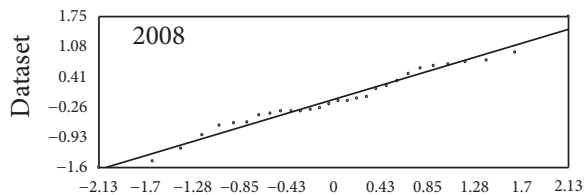

Standard normal value

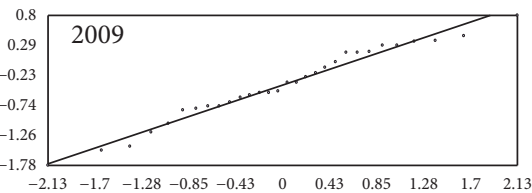

Standard normal value

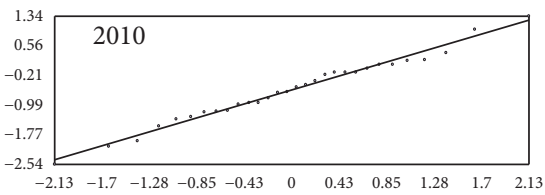

Standard normal value

FIGURE 4: Normal QQ plot based on twelve-month SPI over the period of 1981-2010 for 30 meteorological stations of Bangladesh (horizontal axis represents the standard normal value and vertical axis represents the datasets of SPI). 


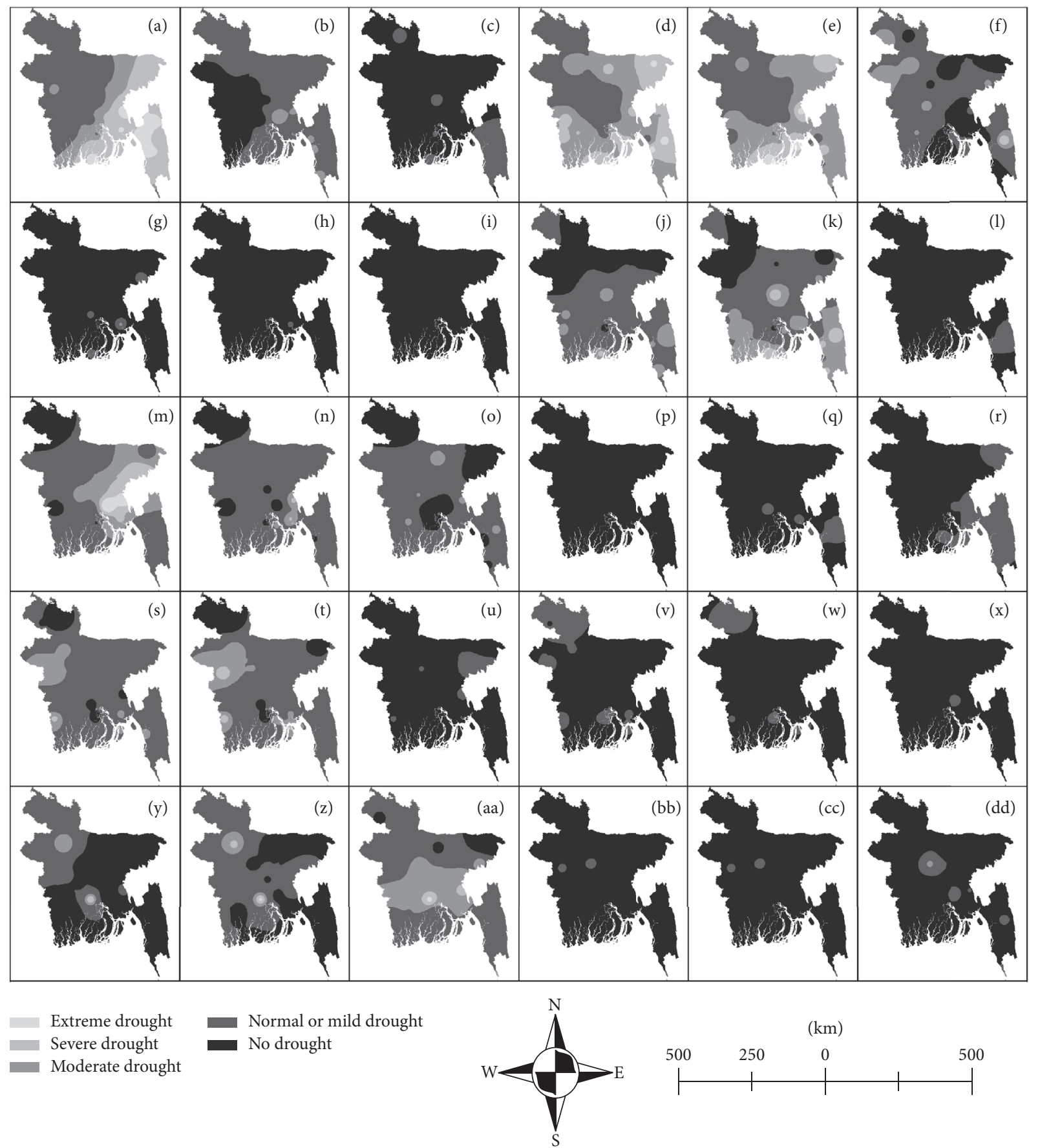

FIGURE 5: Spatiotemporal distribution of meteorological drought of Bangladesh over the periods of 1981-1990.

Few parts of Chittagong, Khulna, and Dhaka faced severe drought. The rest of the parts of the country had normal or mild drought (Figure 5(j)). Most of the parts of Rangpur and Rajshahi had no drought. The north-eastern part of the country had no drought too. Based on six-month SPI, extreme drought was seen in few parts of Dhaka and Chittagong. Most of the parts of Khulna and Chittagong had moderate drought. Normal drought existed in rest of the other parts of the country (Figure 5(k)). Normal drought was found in most of the parts of Chittagong. No drought was seen in the rest of the parts of the country based on twelvemonth SPI in the year of 1984 (Figure 5(l)).

The maps (Figures 5(m), 5(n), and 5(o)) show the conditions of 1985 based on an interval of 3, 6, and 12 months, respectively. In 1985, the country faced almost all types of drought (Figures 5(m), 5(n), and 5(o)). Extreme drought was seen in the eastern part of the country (Figure $5(\mathrm{~m})$ ). Normal drought existed in some parts of the country (Figure 5(n)). 


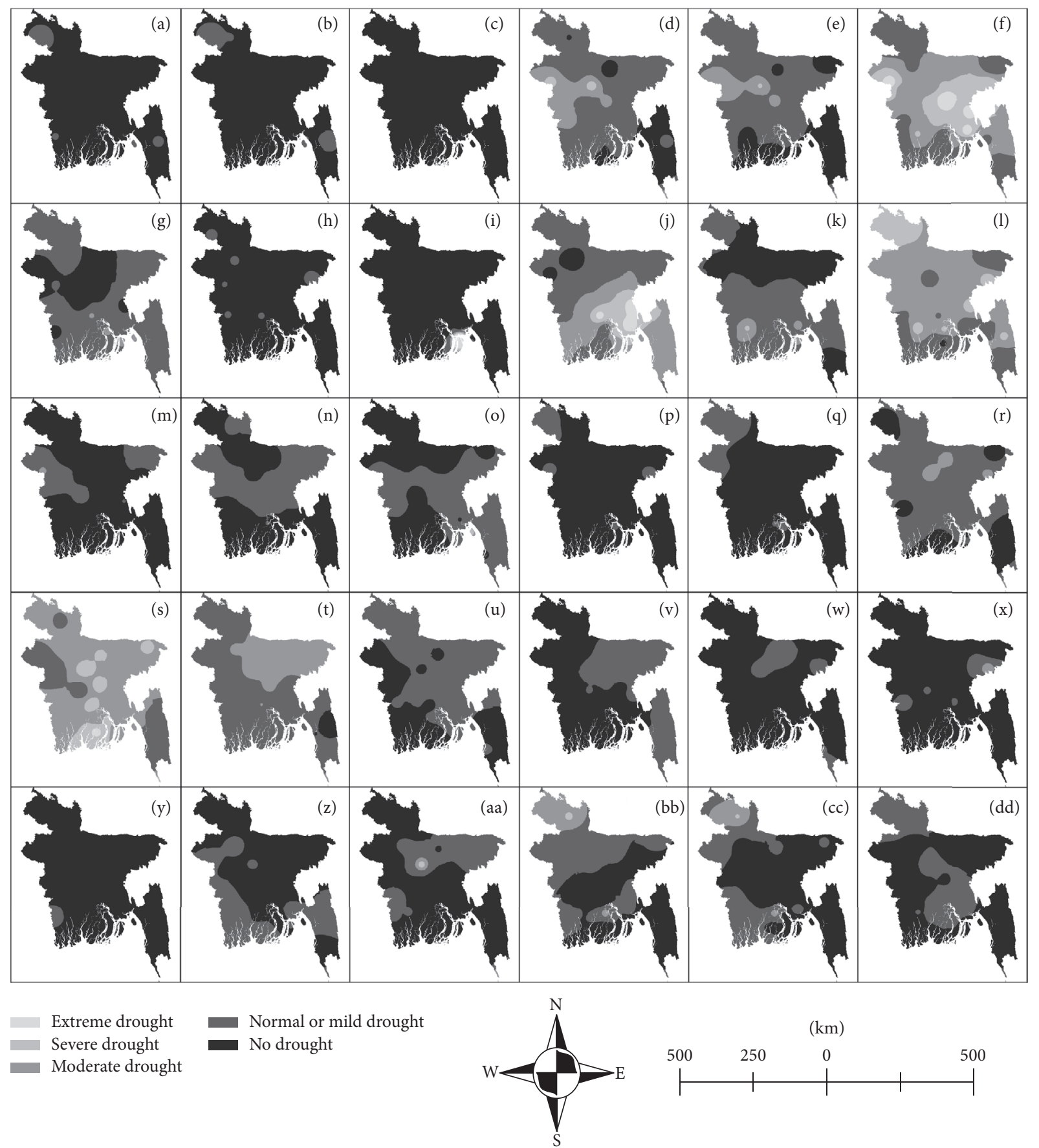

FIGURE 6: Spatiotemporal distribution of meteorological drought of Bangladesh over the period of 1991-2000.

Severe drought was seen in some parts of Mymensingh, Dhaka, Khulna, and Chittagong. Major portions had normal drought (Figure 5(o)).

The maps (Figures 5(p), 5(q), and 5(r)) show the conditions of different parts of the country in 1986 on the basis of 3,6, and 12 months interval. No drought was found based on three-month and six-month SPI (Figures 5(p) and $5(\mathrm{q})$ ). Normal drought was seen in few parts like Madaripur and Maijdi and some portions of Chittagong (Figure 5(q)).
Normal drought was seen in the north-eastern and southeastern parts of the country. The rest of the parts faced no drought (Figure 5(r)). The maps (Figures 5(s), 5(t), and 5(u)) show the conditions in 1987 on the basis of 3, 6, and 12 months interval. Most of the parts of the country faced normal drought. Some parts of Rajshahi and Khulna had severe drought. No drought was seen in few parts of Rangpur and Barisal district (Figure 5(s)). No drought was seen in Rangpur and few parts of Sylhet and Barisal. Normal drought 


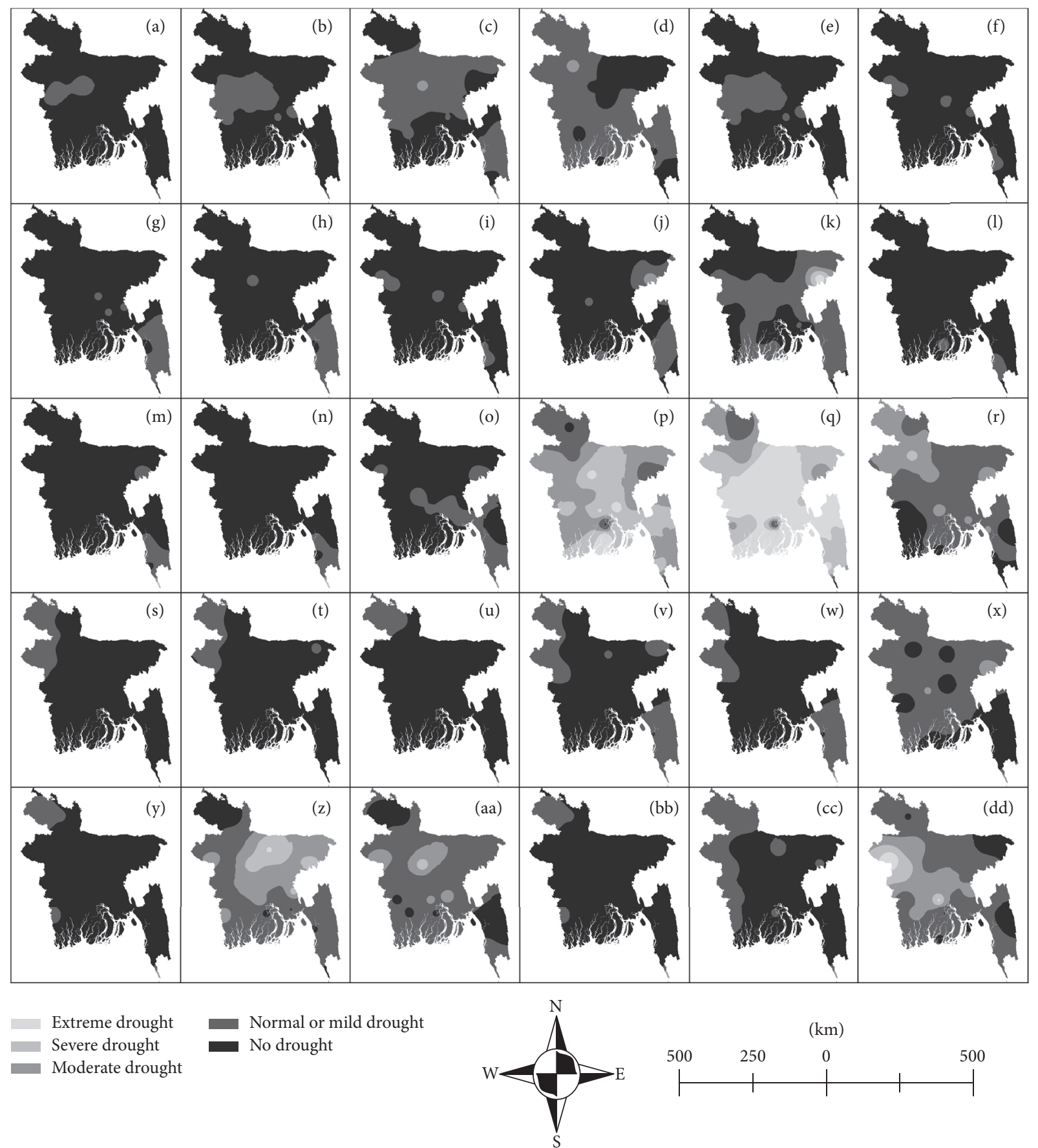

FIGURE 7: Spatiotemporal distribution of meteorological drought of Bangladesh over the period of 2001-2010.

existed in most of the areas of the country. Rajshahi and Khulna faced severe drought (Figure 5(t)). Most of the parts of Sylhet and a small part of Dhaka faced normal drought. No drought was seen in rest of the parts of the country (Figure 5(u)). The maps (Figures 5(v), 5(w), and 5(x)) show the conditions of the country in 1988 on an interval of 3, 6, and 12 months, respectively. Rangpur faced normal drought.

Few parts of Rajsahi, Khulna, Barisal, and Chittagong faced similar conditions too. No drought was seen in the rest of the parts of the country (Figure 5(v)). Major parts of Rangpur and a small part of Barisal faced normal drought. The rest of the parts of the country had no drought (Figure 5(w)). Comilla faced normal drought. No drought was seen in the rest of the parts of the country (Figure 5(x)). The maps (Figures $5(\mathrm{y}), 5(\mathrm{z})$, and $5(\mathrm{aa}))$ show the condition of the country in 1989 on an interval of 3, 6, and 12 months, respectively. The north-eastern and most of the southern parts of the country faced no drought. Few parts of Rajshahi had severe drought 
and a part of Barisal had extreme drought. The majority of Rangpur, Rajshahi, and Barisal had normal drought. No drought was seen in the rest of the parts (Figure 5(y)). No drought was seen in Sylhet, Mymensingh, and Chittagong and in few parts of Khulna and Barisal. A small part of Rajshahi and Madaripur faced severe drought. Normal conditions existed in most of the parts (Figure 5(z)). Few parts of Sylhet, Rangpur, and Mymensingh had no drought. Most of the parts of Rangpur, Rajshahi, and Chittagong faced normal drought. Madaripur had severe drought. Moderate condition was found in the mid regions of the country (Figure 5(aa)).

The maps (Figures 5(bb), 5(cc), and 5(dd)) show the conditions of 1990 with an interval of 3-, 6-, and 12-month SPI, respectively. Severe drought was seen in Tangail and Ishurdi. No drought was seen in the rest of the parts of the country (Figure 5(bb)). The condition was quite similar here. Tangail and Ishurdi faced severe drought and the parts of the country had no drought (Figure 5(cc)). A major portion of Dhaka and Maijdi and a small part of Chittagong had severe drought. No drought was seen in the rest of the parts of the country (Figure 5(dd)).

3.4. Assessment of Drought in the Decade of 1991-2000 in Bangladesh. Figure 6 marks the drought conditions of different parts of Bangladesh during 1991-2000. The maps (Figures 6(a), 6(b), and 6(c)) show the conditions of different parts of the country in 1991 on an interval of 3-, 6-, and 12-month SPI, respectively. No drought was seen in most of the parts of the country. A major part of Rangpur and a small portion of Chittagong had normal drought condition (Figure 6(a)). Severe drought was found in parts of Rajshahi, Khulna, and Dhaka and a small part of Chittagong based on three-month SPI in 1992. No drought existed in a portion of Mymensingh and Chittagong. The rest of the parts had normal condition (Figure 6(d)). Excluding Ishurdi, a portion of Dhaka and Comilla faced severe drought (Figure 6(e)). Moderate condition was found in Mymensingh and Rajshahi regions. Few parts of Sylhet, Dhaka, and Comilla had both severe and extreme drought distributions (Figure 6(f)). In 1993, excluding some areas of Mymensingh, Dhaka, and Rajshahi, most of the parts of the country had normal drought in this period (Figure 6(g)). No drought was seen in most of the parts of the country. Normal drought prevailed in very few portions of Rajshahi, Khulna, and Barisal regions (Figure 6(h)) based on six-month SPI.

The year of 1994 is a drought prone year when most of the parts of the country had drought conditions. Some parts of Chittagong and a portion of Dhaka and Khulna had moderate drought. Comilla had severe drought (Figure 6(j)). Sylhet, Mymensingh, and Cox's Bazar and few parts of Rajshahi and Rangpur had no drought. Extreme and severe drought was seen in Khulna. The rest of the parts had normal drought (Figure 6(k)). Severe drought was found in Rangpur and some parts of Khulna and Chittagong. Normal drought was seen in some parts of Sylhet, Dhaka, Khulna, and Chittagong (Figure 6(l)).
In 1995, few parts of Rajshahi, Khulna, and Sylhet faced severe drought. No drought was seen in rest of the parts of the country (Figure $6(\mathrm{~m})$ ). No drought was found in some regions of Rangpur, Rajshahi, Mymensingh, Khulna, and Chittagong. Normal drought prevailed in the rest of the parts (Figure 6(n)). The northern and south-western parts of the country had no drought. The rest of the parts faced normal drought (Figure 6(o)). Without some parts of Dinajpur and Rajshahi, the parts of the country had no drought in short and medium short-term periods while normal drought existed in most of the parts of the country based on twelve-month SPI in 1996. Most of the parts had no drought. Normal drought was found in some parts of Rangpur and Sylhet (Figure 6(p)).

Most of the parts of Rangpur and some portions of Rajshahi had normal drought condition. No drought was seen in the rest of the parts (Figure 6(q)). No drought was found in some parts of Rangpur, Slhet, Khulna, Barisal, and Chittagong. Some portions of Dhaka and Mymensingh faced severe drought (Figure 6(r)). In 1997, based on threemonth SPI analysis severe drought was found in few parts of Mymensingh, Dhaka, and Sylhet (Figure 6(s)). Again, most of the western parts of the country and a major portion of Chittagong faced normal drought. Severe drought existed in parts of Sylhet, Mymensingh, and Dhaka. No drought was found in a portion of Chittagong (Figure 6(t)). Parts of Rajshahi, Khulna, Mymensingh, and Chittagong had no drought. The rest of the parts of the country faced normal drought (Figure 6(u)). Most of the parts of the country were free from drought in 1998 and 1999 while some parts of eastern regions had normal drought conditions (Figures 6(v), 6(w), and 6(x)) and some parts of Rajshahi, Khulna, Dhaka, and Chittagong had severe drought. The rest of the parts had no drought (Figures $6(\mathrm{y})$ and $6(\mathrm{z})$ ).

No drought was found in Rangpur, Comilla, Barisal, and Chittagong and few parts of Rajshahi and Khulna. Severe drought was found in Sylhet and Mymensingh while a portion of Dhaka faced extreme drought (Figure 6(aa)). In 2000 extreme drought was found in a small part of Rangpur. Majority of Rangpur had severe drought. No drought occurred in Chittagong and few parts of Sylhet, Dhaka, Comilla, and Khulna (Figure 6(bb)). No drought occurred in Chittagong, parts of Comilla, Dhaka, Rajshahi, and Sylhet. Severe and extreme drought was seen in parts of Rangpur. The rest of the parts had normal drought conditions (Figure 6(cc)). Most of the parts of Rajshahi, Khulna, Sylhet, and Chittagong had no drought during this period. Rangpur, Dhaka, Comilla, and Barisal faced severe drought (Figure 6(dd)).

3.5. Assessment of Drought in the Decade of 2001-2010 in Bangladesh. The maps in the Figure 7 show the different conditions of drought in different parts of the country from 2001 to 2010.

In 2001 no drought was seen in most of the parts of the country. Normal or mild drought was observed in some parts of Rajshahi (Figure 7(a)). Parts of Rajshahi, Dhaka, and Khulna and a small portion of Comilla faced normal drought. The rest of the parts of the country had no drought conditions 
(Figure 7(b)). The capital city Dhaka faced severe drought. No drought was found in Rangpur and some parts of Sylhet, Chittagong, Barisal, and Khulna. Mymensingh and the rest of Sylhet, Chittagong, Rajshahi, and Khulna had normal drought during this period (Figure 7(c)). A small portion of Rajshahi faced severe drought in 2002. No drought was found in Sylhet and some parts of Dhaka, Chittagong, and Khulna. The rest of the parts faced normal drought (Figure $7(d)$ ). Some parts of Rajshahi, Dhaka, and Khulna and a very small portion of Comilla had normal drought. The rest of the parts of the country did not face any drought (Figure $7(\mathrm{e})$ ). No drought occurred in most of the parts of the country. Ishurdi and Pabna and very small portions of Comilla and Chittagong were found to have normal drought (Figure 7(f)).

In 2003 no drought was seen in most of the areas. Chittagong and some parts of Comilla faced normal drought (Figure $7(\mathrm{~g})$ ). Parts of Dhaka and Chittagong had normal drought. The rest of the parts faced no drought (Figure 7(h)). Most of the parts of the country faced no drought. Small portions of Rajshahi, Dhaka, and Chittagong had normal drought (Figure 7(i)).

A portion of Sylhet faced severe drought conditions in 2004 (Figures 7(i), 7(k), and 7(1)). Many areas of the county faced normal drought (Figure $7(\mathrm{k})$ ) and no drought (Figure 7(l)). The majority of the parts had no drought in 2005 (Figures 7(m), 7(n), and 7(o)). In 2006 no drought was observed in a small portion of Rangpur. The rest of the parts of Rangpur and small portion of Sylhet and Barisal had normal drought. Parts of Sylhet, Chittagong, Barisal, and Khulna had moderate drought. Mymensingh, Dhaka, and Comilla faced extreme and severe drought (Figure $7(\mathrm{p})$ ). Extreme drought was seen in major portions of the country. Severe drought was found in parts of Rajshahi, Sylhet, Chittagong, and Khulna. Rangpur had different distributions of drought condition (Figure 7(q)). Some parts of Khulna and Chittagong faced no drought. Severe drought was observed in Bogra. Most of the parts of Rajshahi and Rangpur had moderate drought (Figure $7(\mathrm{r})$ ). Most of parts of northern-western part had normal drought (Figures 7(s), 7(t), and 7(u)).

The major part of the country had no drought in 2007 and 2008 while normal drought conditions existed in most parts of the country. Madaripur regions faced severe drought (Figure 7(x)). In 2009, Rangpur and some parts of Khulna had normal drought. No drought was found in the rest of the parts of the country (Figure $7(y)$ ). No drought was seen in Rangpur. Most of the parts in the west and south of the country had normal drought. Dhaka, Mymensingh and Sylhet faced severe drought (Figure $7(\mathrm{z})$ ). No drought was seen in parts of Rangpur, Chittagong and some portion of Khulna. Major parts of the country had normal drought while a small portion of Dhaka faced severe drought. Potions of Rajshahi, Dhaka, Mymensingh and Comilla had moderate drought during this period (Figure $7(\mathrm{aa})$ ).

In 2010 no drought was observed in most parts of the country. Rangpur and a very small portion of Khulna had normal drought (Figure 7(bb)). Rangpur and the western parts of the country had normal drought. The same condition was also seen in a part of Mymensingh. No drought was seen in the rest of the parts of the country (Figure $7(\mathrm{cc})$ ). Extreme and severe drought was seen in Ishurdi and Pabna regions of the country. Madaripur too faced severe drought. A small portion of Rangpur, Sylhet, and Chittagong had no drought. Parts of Rajshahi, Khulna, and Dhaka had moderate drought conditions. The rest of the parts of Mymensingh, Rangpur, Dhaka, Khulna, Barisal, and Chittagong faced normal drought (Figure $7(\mathrm{dd})$ ).

3.6. Characteristics of Meteorological Drought in Bangladesh during 1981-2010. The results indicated that temporarily the rainfall intensity, duration, and spatial consequences had a strong anomaly. Drought varied spatially in Bangladesh over the study period. Some areas had no drought in the short term (three-month SPI) and medium short-term interval (six-month SPI) whereas these areas had drought in the longterm (twelve-month SPI). The overall result indicated that the drought conditions were dynamic across Bangladesh (Figures 5,6 , and 7).

In the first decade drought was found in 1981, 1982, 1985, 1987, and 1989 based on three-month SPI. In the second decade drought was more prominent in 1992, 1994, and 1997 and in the third decade (2001-2010) drought occurred in 2002, 2006, 2009, and 2010. During the first half of the period between (1981-2000) and (2001-2010), more droughts occurred based on six-month SPI but in later half, the country had experienced more droughts based on twelvemonth SPI (Figures 5, 6, and 7). In general, the northern areas of Bangladesh are more prone to drought occurrences compared to the rest of the country. According to six-month SPI calculation, severe to extreme meteorological drought occurred in 1982, 1984, 1987, 1989, 1997, 2006, and 2009 (Figures 5, 6, and 7). Moderate to severe meteorological drought occurred in 1992, 1994, and 2010 on the basis of 12month SPI calculation (Figures 5, 6, and 7).

Drought hit different parts of northern Bangladesh. The southwest areas of the country, Jessore and Satkhira, and the coastal areas, including Bhola and Patuakhali, were more prone to meteorological drought.

Extreme drought occurred in 1994 and moderate drought occurred in 1997, 2006, and 2007 in some parts of the south and south-western areas. However, most of the central part of Bangladesh was comparatively free of meteorological drought. Moderate drought occurred in some parts of central region in 1994, 2004, 2003, 2009, and 2010 (Figures 5, 6, and 7).

The eastern part of the country was comparatively free of meteorological drought. In contrast, in the south eastern part, the Chittagong hill tract areas experienced much drought compared to other areas, in 1994, 2005, 2006, and 2008 (Figures 5, 6, and 7).

3.7. Decadal Variations in Meteorological Drought in Bangladesh during 1981-2010. Drought is a normal phenomenon. Statistical analysis of Kruskal-Wallis statistics for decadal analysis indicates that there was no variation among the 
TABLE 5: Kruskal-Wallis statistics for decadal variation for the period of 1981-1990, 1991-2000, and 2001-2010 based on three-month SPI.

\begin{tabular}{lc}
\hline Station name & $P$ value \\
\hline Barisal & 0.151 \\
Bhola & 0.517 \\
Bogra & 0.696 \\
Chandpur & 0.42 \\
Chittagong & 0.796 \\
Comilla & 0.765 \\
Cox's Bazar & 0.97 \\
Dhaka & 0.996 \\
Dinajpur & 0.642 \\
Faridpur & 0.946 \\
Hatiya & 0.229 \\
Ishurdi & 0.998 \\
Jessore & 0.755 \\
Khepupara & 0.141 \\
Khulna & 0.318 \\
Kutubdia & 0.612 \\
M. Court & 0.069 \\
Madaripur & 0.555 \\
Mymensinghh & 0.985 \\
Patuakhali & 0.251 \\
Rajshahi & 0.956 \\
Rangamati & 0.703 \\
Rangpur & 0.151 \\
Sandwip & 0.546 \\
Satkhira & 0.683 \\
Sitakunda & 0.732 \\
Srimangal & 0.871 \\
Tangail & 0.342 \\
\hline & 0.842 \\
Teknaf & 0.939 \\
\hline
\end{tabular}

three decades over the period of 1981-2010 based on threemonth SPI at 5\% significant level and variations in M. Court were found at $10 \%$ significant level (Table 5). There were no variations found among the decades based on six-month SPI (Table 6). Variations in drought conditions among the three decades of Khutubdia were found at $5 \%$ significant level based on twelve-month SPI (Table 7). Again Chandpur, Hatiya, and Rangamati had decadal variation in drought conditions at $10 \%$ significant level based on twelve-month SPI (Table 7).

\section{Conclusions}

The meteorological drought being a changing phenomenon in Bangladesh is mostly unpredictable over the study period. The spatiotemporal character of the meteorological drought of Bangladesh indicated that the country was vulnerable to drought incidents on the basis of the past rainfall records. The meteorological drought varied due to the temporal and
TABLE 6: Kruskal-Wallis statistics for decadal variation for the period of 1981-1990, 1991-2000, and 2001-2010 based on six-month SPI.

\begin{tabular}{lc}
\hline Station Name & $P$ value \\
\hline Barisal & 0.202 \\
Bhola & 0.647 \\
Bogra & 0.923 \\
Chandpur & 0.823 \\
Chittagong & 0.221 \\
Comilla & 0.351 \\
Cox's Bazar & 0.453 \\
Dhaka & 0.818 \\
Dinajpur & 0.514 \\
Faridpur & 0.75 \\
Hatiya & 0.446 \\
Ishurdi & 0.628 \\
Jessore & 0.814 \\
Khepupara & 0.246 \\
Khulna & 0.922 \\
Kutubdia & 0.161 \\
M. Court & 0.141 \\
Madaripur & 0.822 \\
Mymensinghh & 0.94 \\
Patuakhali & 0.36 \\
Rajshahi & 0.746 \\
Rangamati & 0.217 \\
Rangpur & 0.202 \\
Sandwip & 0.651 \\
Satkhira & 0.871 \\
Sitakunda & 0.231 \\
Srimangal & 0.882 \\
Tangail & 0.448 \\
Teknaf & 0.823 \\
& 0.869 \\
\hline
\end{tabular}

spatial pattern of rainfall occurrences. The SPI depicted that the drought conditions plunged dramatically in some years whereas in other years they remained stable. Drought hits Bangladesh on an average of 2.5 years which was alarming for agriculture practices and environment issues. Drought was more prominent in northern and south-western regions of Bangladesh compared to the rest of the areas of the country. SPI is only based on rainfall. For this, it is easy to detect, monitor, and forecast meteorological drought in a region. The present study helps in understanding drought in different areas in Bangladesh using past rainfall performance. Further, the results may help in planning to take necessary actions to manage regional drought and reduce the adverse impacts of drought across Bangladesh.

\section{Competing Interests}

The authors declare no conflict of interests. 
TABLE 7: Kruskal-Wallis statistics for decadal variation for the period of 1981-1990, 1991-2000, and 2001-2010 based on twelve-month SPI.

\begin{tabular}{|c|c|}
\hline Station name & $P$ value \\
\hline Barisal & 0.401 \\
\hline Bhola & 0.285 \\
\hline Bogra & 0.564 \\
\hline Chandpur & 0.079 \\
\hline Chittagong & 0.623 \\
\hline Comilla & 0.673 \\
\hline Cox’s Bazar & 0.907 \\
\hline Dhaka & 0.756 \\
\hline Dinajpur & 0.882 \\
\hline Faridpur & 0.258 \\
\hline Hatiya & 0.067 \\
\hline Ishurdi & 0.263 \\
\hline Jessore & 0.179 \\
\hline Khepupara & 0.337 \\
\hline Khulna & 0.503 \\
\hline Kutubdia & 0.022 \\
\hline M. Court & 0.172 \\
\hline Madaripur & 0.149 \\
\hline Mymensinghh & 0.436 \\
\hline Patuakhali & 0.106 \\
\hline Rajshahi & 0.284 \\
\hline Rangamati & 0.074 \\
\hline Rangpur & 0.401 \\
\hline Sandwip & 0.141 \\
\hline Satkhira & 0.94 \\
\hline Sitakunda & 0.576 \\
\hline Srimangal & 0.188 \\
\hline Sylhet & 0.168 \\
\hline Tangail & 0.32 \\
\hline Teknaf & 0.285 \\
\hline
\end{tabular}

\section{Authors' Contributions}

Md. Anarul Haque Mondol designed the research idea, analyzed the data, and wrote the manuscript; Iffat Ara contributed in writing and provided critical evaluation of the manuscript. Subash Chandra Das revised the manuscript critically and provided important intellectual content.

\section{Acknowledgments}

The authors are grateful to the Centre for the Assessment of Natural Hazards and Proactive Planning \& Laboratory of Reclamation Works and Water Resources Management of National Technical University of Athens for offering the free "DrinC" software. Thanks are due to Bangladesh Meteorological Department (BMD) for providing the rainfall data.

\section{References}

[1] D. A. Wilhite, "Drought as a natural hazard: concepts and definitions," in Drought: A Global Assessment, pp. 3-18, Routledge, London, UK, 2000.

[2] A. M. Omer, "Energy, environment and sustainable development," Renewable and Sustainable Energy Reviews, vol. 12, no. 9, pp. 2265-2300, 2008.

[3] Z. Li, T. Zhou, X. Zhao et al., "Assessments of drought impacts on vegetation in China with the optimal time scales of the climatic drought index," International Journal of Environmental Research and Public Health, vol. 12, no. 7, pp. 7615-7634, 2015.

[4] S. Shahid, "Spatial and temporal characteristics of droughts in the western part of Bangladesh," Hydrological Processes, vol. 22, no. 13, pp. 2235-2247, 2008.

[5] M. A. Abedin, U. Habiba, and R. Shaw, "Chapter 10 Health: impacts of salinity, arsenic and drought in South-western Bangladesh," in Environment Disaster Linkages (Community, Environment and Disaster Risk Management, Volume 9), vol. 9, pp. 165-193, Emerald Group Publishing, West Yorkshire, UK, 2012.

[6] R. Nagarajan, "Drought indices," in Drought Assessment, pp. 160-204, Springer, Dordrecht, The Netherlands, 2009.

[7] T. B. Mckee, N. J. Doesken, and J. Kleist, "The relationship of drought frequency and duration to time scales," in Proceedings of the AMS 8th Conference on Applied Climatology, pp. 179-184, January 1993.

[8] A. I. Keka, I. Matin, M. Rahman, and D. Banu, "Analysis of Drought in Eastern Part of Bangladesh," Daffodil International University Journal of Science and Technology, vol. 7, no. 1, pp. 2027, 2012.

[9] H. Murad and A. S. Islam, "Drought assessment using remote sensing and GIS in north-west region of Bangladesh," in Proceedings of the 3rd International Conference on Water \& Flood Management, pp. 797-804, Dhaka, Bangladesh, January 2011.

[10] M. Rafiuddin and B. Dash, "Diagnosis of drought in Bangladesh using standardized precipitation index," in Proceedings of the International Conference on Environment Science and Engineering (ICESE '11), vol. 8, pp. 184-187, Bali, Indonesia, April 2011.

[11] H. Brammer, "Drought in Bangladesh: lessons for planners and administrators," Disasters, vol. 11, no. 1, pp. 21-29, 1987.

[12] E. Kampragou, S. Apostolaki, E. Manoli, J. Froebrich, and D. Assimacopoulos, "Towards the harmonization of waterrelated policies for managing drought risks across the EU," Environmental Science and Policy, vol. 14, no. 7, pp. 815-824, 2011.

[13] F. Lihua, "Method of quantitative expression of drought magnitude and drought disaster degree," System Sciences and Comprehensive Studies in Agriculture, vol. 3, p. 19, 2003.

[14] S. Sirdaş and Z. Şen, "Spatio-temporal drought analysis in the Trakya region, Turkey," Hydrological Sciences Journal, vol. 48, no. 5, pp. 809-820, 2003.

[15] A. K. Mishra and V. P. Singh, "A review of drought concepts," Journal of Hydrology, vol. 391, no. 1-2, pp. 202-216, 2010.

[16] N. R. Patel, P. Chopra, and V. K. Dadhwal, "Analyzing spatial patterns of meteorological drought using standardized precipitation index," Meteorological Applications, vol. 14, no. 4, pp. 329336, 2007.

[17] P. Chopra, Drought risk assessment using remote sensing and GIS: a case study of Gujarat [ME thesis], Indian Institute of 
Remote Sensing, Dehradun, India; International Institute for Geo-information Science and Earth Observation, Enschede, The Netherlands, 2006.

[18] M. Alamgir, S. Shahid, M. K. Hazarika, S. Nashrrullah, S. B. Harun, and S. Shamsudin, "Analysis of meteorological drought pattern during different climatic and cropping seasons in Bangladesh," Journal of the American Water Resources Association, vol. 51, no. 3, pp. 794-806, 2015.

[19] A. C. Steinemann, "Using climate forecasts for drought management," Journal of Applied Meteorology and Climatology, vol. 45, no. 10, pp. 1353-1361, 2006.

[20] N. Eriyagama, V. Y. Smakhtin, and N. Gamage, "Mapping drought patterns and impacts: a global perspective," IWMI Research Report 133, IWMI, 2009.

[21] S. Solomon, Climate Change 2007-The Physical Science Basis: Working Group I Contribution to the Fourth Assessment Report of the IPCC, vol. 4, Cambridge University Press, Cambridge, UK, 2007.

[22] M. Zimmermann, K. F. Glombitza, and B. Rothenberger, Disaster Risk Reduction Programme for Bangladesh, The Swiss Agency for Development and Cooperation (SDC), Directorate of Humanitarian Aid and SHA, Bern, Switzerland, 2010.

[23] A. Alam, A. H. M. Saadat, M. S. Rahman, and M. A. B. Barkotulla, "Spatial analysis of rainfall distribution and its impact on agricultural drought at Barind region, Bangladesh," Rajshahi University Journal of Environmental Science, vol. 1, no. 1, pp. 40-50, 2011.

[24] A. T. M. Jahangir Alam, A. H. M. Saadat, M. Sayedur Rahman, and S. Rahman, "Spatio-temporal variation of agricultural drought in the barind region of Bangladesh: an application of a Markov chain model," Irrigation and Drainage, vol. 63, no. 3, pp. 383-393, 2014.

[25] K. S. Akter and M. M. Rahman, "Spatio-temporal quantification and characterization of drought patterns in bangladesh," Journal of Water and Environment Technology, vol.10, no. 3, pp. 277-288, 2012.

[26] S. Shahid and H. Behrawan, "Drought risk assessment in the western part of Bangladesh," Natural Hazards, vol. 46, no. 3, pp. 391-413, 2008.

[27] M. Rafiuddin, B. K. Dash, F. Khanam, and M. N. Islam, "Diagnosis of drought in Bangladesh using standardized precipitation index," in Proceedings of the in International Conference on Environment Science and Engineering, April 2011.

[28] Z. Karim, A. Ibrahim, A. Iqbal, and M. Ahmed, Drought in Bangladesh Agriculture and Irrigation Schedules for Major Crops, no. 34, Bangladesh Agricultural Research Council, Dhaka, Bangladesh, 1990.

[29] Z. Karim and A. Iqbal, Impact of Land Degradation in Bangladesh: Changing Scenario in Agricultural Land Use, Bangladesh Agricultural Research Center, 2001.

[30] C. Tan, J. Yang, and M. Li, “Temporal-Spatial Variation of Drought Indicated by SPI and SPEI in Ningxia Hui Autonomous Region, China," Atmosphere, vol. 6, no. 10, pp. 1399-1421, 2015.

[31] A. Shahabfar and J. Eitzinger, "Spatio-temporal analysis of droughts in semi-arid regions by using meteorological drought indices," Atmosphere, vol. 4, no. 2, pp. 94-112, 2013.

[32] M. A. Mondol, S. C. Das, and M. N. Islam, "Application of Standardized Precipitation Index to assess meteorological drought in Bangladesh," Jàmbá Journal of Disaster Risk Studies, vol. 8, no. 1, 14 pages, 2016.
[33] C. A. Karavitis, S. Alexandris, D. E. Tsesmelis, and G. Athanasopoulos, "Application of the Standardized Precipitation Index (SPI) in Greece," Water, vol. 3, no. 3, pp. 787-805, 2011.

[34] Q. Zhang, C.-Y. Xu, and Z. Zhang, "Observed changes of drought/wetness episodes in the Pearl River basin, China, using the standardized precipitation index and aridity index," Theoretical and Applied Climatology, vol. 98, no. 1-2, pp. 89-99, 2009.

[35] D. Tigkas, H. Vangelis, and G. Tsakiris, "DrinC: a software for drought analysis based on drought indices," Earth Science Informatics, vol. 8, no. 3, pp. 697-709, 2014.

[36] A. Cancelliere, G. D. Mauro, B. Bonaccorso, and G. Rossi, "Drought forecasting using the standardized precipitation index," Water Resources Management, vol. 21, no. 5, pp. 801-819, 2007.

[37] L. Giddings, M. Soto, B. M. Rutherford, and A. Maarouf, "Standardized precipitation index zones for México," Atmosfera, vol. 18, no. 1, pp. 33-56, 2005.

[38] J. A. T. M. Alam, S. M. Rahman, and A. H. M. Saadat, "Monitoring meteorological and agricultural drought dynamics in Barind region Bangladesh using standard precipitation index and Markov chain model," International Journal of Geomatics and Geosciences, vol. 3, no. 3, p. 511, 2013.

[39] M. G. Ali, K. Younes, A. Esmaeil, and T. Fatemeh, "Assessment of geostatistical methods for spatial analysis of SPI and EDI drought indices," World Applied Sciences Journal, vol. 15, no. 4, pp. 474-482, 2011.

[40] F. Attorre, M. Alfo, M. De Sanctis, F. Francesconi, and F. Bruno, "Comparison of interpolation methods for mapping climatic and bioclimatic variables at regional scale," International Journal of Climatology, vol. 27, no. 13, pp. 1825-1843, 2007.

[41] G. Y. Lu and D. W. Wong, "An adaptive inverse-distance weighting spatial interpolation technique," Computers and Geosciences, vol. 34, no. 9, pp. 1044-1055, 2008.

[42] M. Moazami, S. Feiznia, M. Kholghi, and A. Malekian, "Using SPI and PN indices for determination of drought in the Fars Province," Journal of Applied Hydrology, vol. 2, no. 1, pp. 1-9, 2015. 

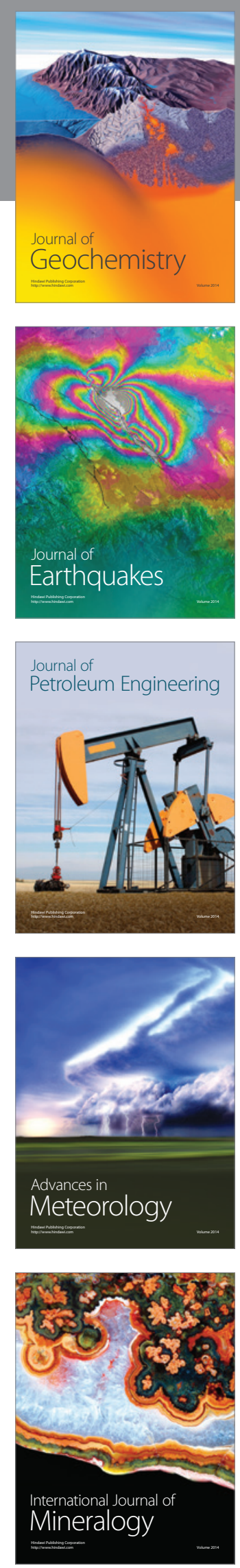
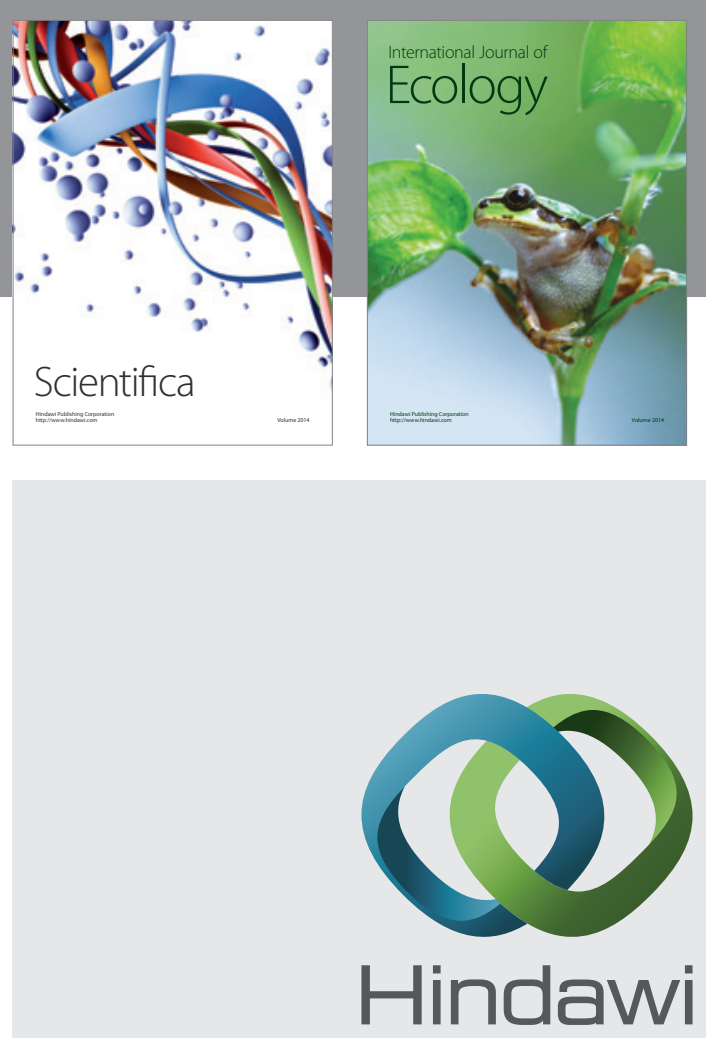

Submit your manuscripts at

https://www.hindawi.com
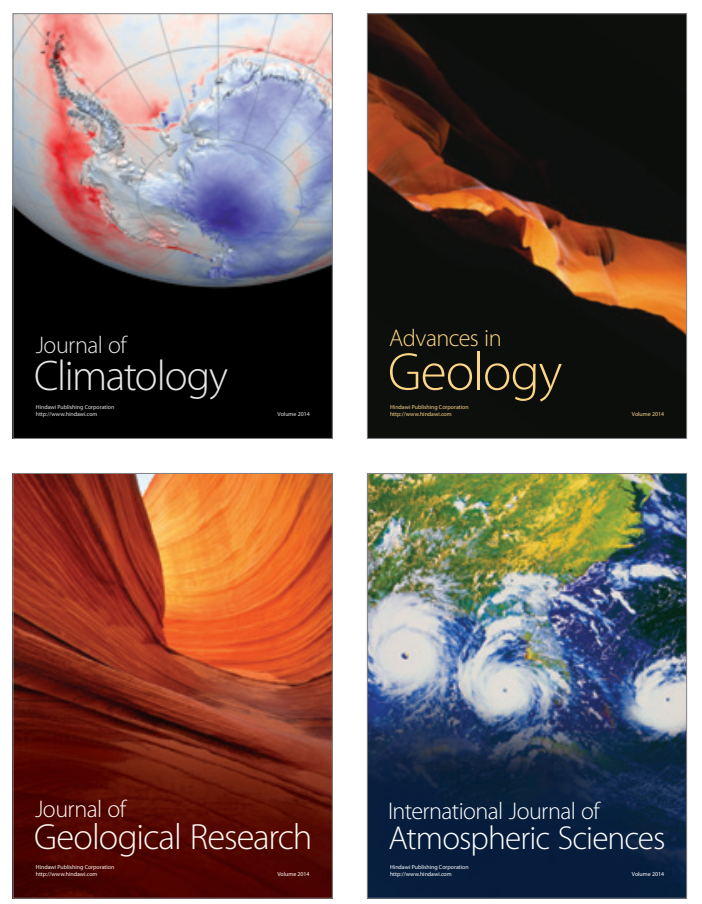

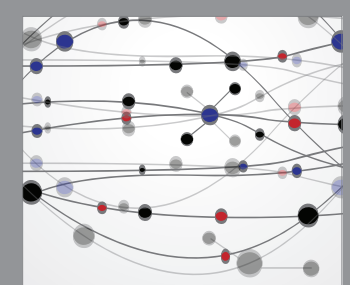

The Scientific

\section{World Journal}
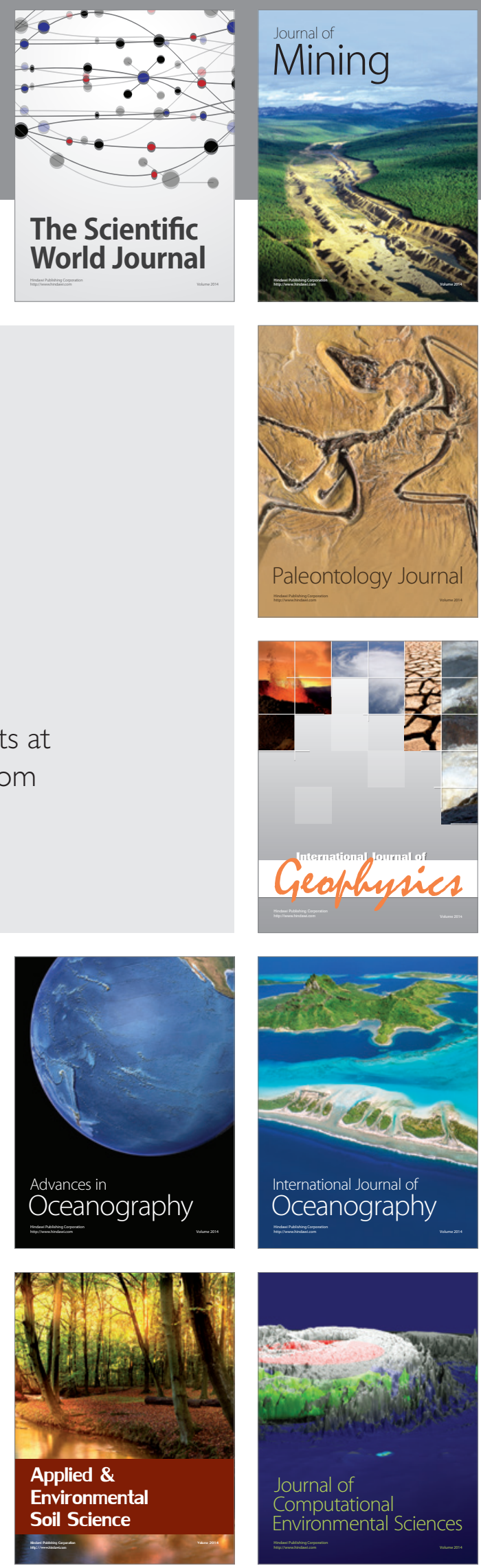